\title{
Biomechanical and morphological study of a new elastic mesh (Ciberlastic) to repair abdominal wall defects.
}

\author{
B. Calvo§ ${ }^{\mathrm{a}, \mathrm{d}}$, G. Pascual§ b,d, E. Peña ${ }^{\mathrm{a}, \mathrm{d}}$, B. Pérez-Khöler ${ }^{\mathrm{c}, \mathrm{d}}$, \\ M. Rodríguez ${ }^{\mathrm{c}, \mathrm{d}}$, J.M. Bellón ${ }^{\mathrm{c}, \mathrm{d}}$ \\ ${ }^{a}$ Aragón Institute of Engineering Research (I3A), University of Zaragoza, Spain. \\ ${ }^{\mathrm{b}}$ Department of Medicine and Medical Specialities, Faculty of Medicine and Health Sciences, \\ University of Alcalá, Spain. \\ ${ }^{\mathrm{c}}$ Department of Surgery, Medical and Social Sciences, Faculty of Medicine and Health Sciences, \\ University of Alcalá, Spain. \\ ${ }^{\mathrm{d}}$ Centro de Investigación Biomédica en Red en Bioingeniería, Biomateriales y Nanomedicina \\ (CIBER-BBN), Spain.
}

$\S$ These two authors contributed equally to this work.

* Corresponding author:

Begoña Calvo. Mechanical Engineering Department. c/ Maria de Luna s/n 50018. Zaragoza. Spain. Tel.: +34 876555109; Fax: +34 976762578; Email: bcalvo@unizar.es

\begin{abstract}
The aim of this study was to conduct a preclinical evaluation of the behaviour of a new type of abdominal LW prosthesis (Ciberlastic), which was designed with a non-absorbable elastic polyurethane monofilament (Assuplus, Assut Europe, Italy) to allow greater adaptability to mechanical area requirements and higher bio-mimicking with the newly formed surrounding tissues. Our hypothesis was that an increase in the elasticity of the mesh filament could improve the benefits of LW prostheses. To verify our hypothesis, we compared the short- and long-term behaviour of Ciberlastic and Optilene ${ }^{\circledR}$ elastic commercial meshes by repairing the partially herniated abdomen in New Zealand White rabbits. The implanted meshes were mechanically and histologically assessed at 14 and 180 days post-implant. We mechanically characterized the partially herniated repaired muscle tissue and also determined mesh shrinkage at different post-implant times. This was followed by a histological study in which the tissue incorporation process was analysed over time.

The new prosthesis designed by our group achieved good behaviour that was similar to that of Optilene ${ }^{\circledR}$, one of the most popular LW prostheses on the market, with the added advantage of its elastic property. The mechanical properties are significantly lower than those of the polypropylene Optilene ${ }^{\circledR}$ mesh, and the new elastic mesh meets the basic mechanical requirements for positioning in the abdominal wall, which was also demonstrated by the absence of recurrences after implantation in the experimental model. We found that the growth of a connective tissue rich in collagen over the hernial defect and the proper deposit of the collagen fibres in the regenerated tissue substantially
\end{abstract}


modified the original properties of the mesh, thereby increasing its biomechanical strength and making the whole tissue/mesh stiffer.

Key words: Hernia repair, polyurethane prostheses, biomechanical response, mesh repair.

\section{Introduction}

Until the late $1950 \mathrm{~s}$, the traditional method of repairing hernia defects at the level of the abdominal wall was primary suture repair (Brown and Finch, 2010a). At that time, the first surgical repair that included the use of prosthetic woven/knitted materials in the form of mesh, mainly of polypropylene (PP), began to be performed. Currently, mesh repair is widely accepted as being superior to primary suture repair (EU Hernia Trialists Collaboration, 2002) with approximately one million meshes used in these repairs worldwide each year (Klinge et al., 2002). Several studies have determined that closing hernia defects with prosthetic mesh is associated with a lower rate of recurrence and less postoperative pain (EU Hernia Trialists Collaboration, 2002, Luijenkijk et al., 2000).

Initially, the wall prostheses for hernia repair consisted of resistant, high-density PP that was intended to achieve maximum reinforcement of the affected area. However, it was found that this type of mesh, rather than benefitting the patient, caused restricted movement along with greater foreign body reaction (FBR) and exacerbated fibrotic reaction, leading to higher rates of chronic pain (Poobalan et al., 2003). Therefore, PP meshes have undergone significant changes over time, including modifications in pore size, spatial arrangement and filament diameter, with the goal of obtaining a more suitable mesh that eliminates the undesired effects. Calculations of intraabdominal pressure proved that this was possible without compromising mesh function, and the tensile strength needed to withstand the maximum abdominal pressure is only onetenth of that of most meshes currently on the market (Brown and Finch, 2010a).

The new meshes have been classified as lightweight (LW) and have large pores with a weight of less than $50 \mathrm{~g} / \mathrm{m} 2$ (Cobb et al., 2006). They reduce the inflammatory reaction and therefore have greater flexibility and elasticity (Klinge, 2008), and their superiority over the HW meshes is currently widely accepted. Relevant authors in this field (Conze and Klinge, 1999) have stated that successful clinical results in abdominal hernia surgery depend in large part on a perfect balance between the mechanical properties of the abdominal wall and those of the biomaterial used for the repair. With that balance, once the integration is complete and the implanted mesh and the newly formed tissue constitute a whole, the behaviour of the implant area should mimic that of healthy tissue. Several studies on functional and morphological properties of LW mesh have shown its superior behaviour in the repair of abdominal wall defects compared to HW mesh. It has been shown that long-term physiological abdominal wall compliance could be achieved after LW mesh implantation for hernia repair (Cobb et al., 2006). Clinical prospective studies have also highlighted the benefits of these meshes (O'Dwyer et al., 2005, Conze et al., 2005), demonstrating similar hernia recurrence rates for LW and conventional mesh. Previous 
preclinical experience in our group with animal models proved that lightweight meshes may be considered a good choice in the long term because they show well-structure regenerated tissue (Hernández-Gascón et al., 2012, Pascual et al., 2008) have the benefit of less foreign material being implanted, and preserve the elasticity of the recipient host tissue (Bellón et al., 2009) of the implanted area. However, the use of quasi-elastic materials, such as PP, might cause pain and hernia recurrence because of shearing stresses between the flexible anatomy and the stiffer prosthesis. Recently, Lambertz et al. (2015) constructed a mesh using polyvinylidene fluoride (PVDF) with thermoelastoplastic polyurethane (TPU)filaments, and the new mesh showed both flexibility and structural stability, preserved effective porosity under mechanical strain, and displayed superior biocompatibility compared with mesh made with PVDF alone after 7 and 21 days.

The present study was designed to improve features and benefits of these LW prostheses, taking into account the significant previous experience of our research group. The aim of this study was to conduct a preclinical evaluation of the behaviour of a new type of abdominal LW prosthesis designed with a filament that will allow greater adaptability to mechanical area requirements and higher bio-mimicking with the newly formed surrounding tissue. Based on all requirements studied and the previous work of the group in this field, we have manufactured a prototype of reticular mesh, Ciberlastic (see Figure 3). It is based in a non-absorbable polyurethane monofilament (Assuplus ${ }^{\circledR}$ ) with elastic properties (Simón-Allué et al., 2014) that significantly reduces the high rigidity of the reticular mesh currently on the market. This prototype will be compared with another commercial LW prosthesis called Optilene ${ }^{\circledR}$ which has a similar design and porosity but was developed with a PP filament with lower flexibility (Simón-Allué et al., 2014) and was analysed in a previous study by our group (Hernández-Gascón et al., 2012). Our hypothesis was that an increase of the elasticity of the mesh filament could improve the benefits of LW prostheses. To verify our hypothesis, we compared the short- and long-term behaviour of Ciberlastic and Optilene ${ }^{\circledR}$ commercial meshes by using them to repair the partially herniated abdomen in New Zealand White rabbits. The implanted meshes were mechanically and histologically assessed at 14 and 180 days post-implant. First, we mechanically characterized the partially herniated repaired muscle tissue and also determined mesh shrinkage at the different post-implant times. This was followed by a histological study in which the tissue incorporation process was monitored over time.

\section{Materials and methods}

\subsection{Surgical meshes}

The new lightweight mesh, called Ciberlastic, has been woven with a monofilament 6/0 thread of non-absorbable elastic polyurethane (Assuplus ${ }^{\circledR}$, Assut Europe, Italy (PUe)), see Figure 1. Prior to implant in animals, samples the new mesh were prepared for scanning electron microscopy (SEM), and the porosity and morphological characteristics of the prosthetic monofilament were measured. The control mesh was Optilene ${ }^{\circledR}$ elastic non-absorbable, biocompatible surgical mesh 
(B/Braun, Berlin, Germany). This is an $\left(48 \mathrm{~g} / \mathrm{m}^{2}\right)$ polypropylene monofilament mesh with a large pore size that is called "elastic" because its design allows it to cover a large deformation, but the filament forming the mesh has no elastic property at all.

To check the mechanical properties of the meshes before the preclinical phase, a tensile test of the Ciberlastic mesh were performed. To compare this with previous results obtained by our group for Optilene ${ }^{\circledR}$ meshes, the same protocol that is described in Hernández-Gascón et al. (2011) was used. The mesh samples $(50 \times 15[\mathrm{~mm}])$ were immersed in Hanks solution for 24 $\mathrm{h}$ before tensile test. Uniaxial tensile tests were performed in an INSTRON 5548 microtester with a $50 \mathrm{~N}$ load cell. Contact between the sample and the clamps was improved by attaching sandpaper to the sample using double-sided duct tape. Before the test, a preload of $2 \mathrm{~N}$ was applied to each sample, and a displacement rate of $10 \mathrm{~mm} / \mathrm{min}$ was maintained until the rupture of the sample. To compare the two meshes, force per unit width (Equivalent Piola Stress, EPS) was obtained using the expression $E P S=\frac{F o r c e[N]}{W i d t h[m m]}$, where Force $[\mathrm{N}]$ is the load applied during the test.

Due to the nonlinear character of the curves, the stiffness of the scaffold at different stretch levels was used, defined as the slope of the stress-stretch curve, $E_{p}=\frac{\Delta E P S[\mathrm{~N} / \mathrm{mm}]}{\Delta \lambda}$. Two different moduli were defined depending on the computed stretch levels. Elastic modulus which shows the stiffness at low stretches or $E_{p}^{e}$ (computed at $\lambda=1.01$ ) and tangent modulus at high stretches or $E_{p}^{t}$ (computed at $\lambda=1.3$ ).

\subsection{Experimental animals}

Experimental tests were conducted on New Zealand White rabbits, which is an animal model frequently used for the study of muscle behaviour (Nilsson, 1982a,b, LeBlanc et al., 2002, Johnson et al., 2004, Hilger et al., 2006, Judge et al., 2007, Pascual et al., 2008, Bellón et al., 2009, Pierce et al., 2009). Additional benefits of this model are that it is easy to handle and biologically it is very sensitive to non-biocompatible materials. The model is also highly sensitive to mesh infection. All experiments were performed in accordance with the directives of the European Council (ETS 123) and the European Union (Council Directive 86/609/EEC) regarding the protection of animals used for experimental or other scientific purposes. Twelve male rabbits were acclimatized to the experimental laboratory. During the entire study period, the animals were maintained in a controlled temperature room $\left(22 \pm 1\left[{ }^{\circ} \mathrm{C}\right]\right)$ with a 12 hour light-dark cycle and free access to water and food according to European Union guidelines for animal care (EEC 28871-22A9). The body weight of the rabbits was $2150 \pm 50$ [g] at the beginning of the experiment (baseline, 3 months). All established time points (14 and 180 days) are hereafter referenced to this baseline.

Two study groups were established: the animals in one group $(n=6)$ were implanted with Ciberlastic mesh, and those in the other group $(n=6)$ were implanted with Optilene ${ }^{\circledR}$ mesh. At each of the established time points (14 and 180 days post-implant), three animals were sacrificed. The Optilene ${ }^{\circledR}$ group was used for histological assessment and immunohistochemical 
analysis. The mechanical analysis of Optilene ${ }^{\circledR}$ was previously performed by Hernández-Gascón et al. (2012).

\subsection{Surgical procedure}

To minimize pain, all animals were given $0.05[\mathrm{mg} / \mathrm{kg}]$ buprenorphine 1 hour before and once a day during the three subsequent days after the surgical procedure. Anaesthesia was induced with a mixture of ketamine hydrochloride $(70[\mathrm{mg} / \mathrm{kg}])$, diazepam $(1.5[\mathrm{mg} / \mathrm{kg}])$ and chlorpromazine $(1.5[\mathrm{mg} / \mathrm{kg}])$ administered intramuscularly. Using a sterile surgical technique, $40 \times 40[\mathrm{~mm}]$ defects were created in the lateral wall of the abdomen comprising the plane of the external oblique (EO) and sparing the internal oblique (IO) and transversal abdominis (TA) muscles, parietal peritoneum and skin (see Figure 2). The defects were then repaired by fixing a mesh of the same size to the edges of the defect using a running 4/0 polypropylene suture interrupted at the four corners. That type of fixation, without overlap of the mesh and using a running suture, was chosen because it is the most appropriate for further study of the prosthesis-host tissue interface and because tensions between the mesh and the receptor tissue are better distributed in this type of fixation. In two cases, direction 2 of the mesh (see Figure 1) was longitudinally aligned in the rabbit (see Figure 2(a)) whereas mesh direction 1 (see Figure 1) was transversally aligned (see Figure 2(a)). The skin was closed over the mesh patches with a $3 / 0$ polypropylene running suture. After surgery, the animals were returned to their cages and subjected to regular examinations to check their surgical wounds. All surgical procedures were performed at the Animal Research Centre, Alcalá University. The study protocol was approved by the university's Ethics Committee on Animal Experiments (register code: ES280050001165).

At the established time points, animals in each group were sacrificed in a CO2 chamber. Immediately afterwards, each animal was placed on its back, and the abdominal wall and the skin were dissected to obtain a patch consisting of the repaired defect, including the sutures (see Figure 2(a)).

\subsubsection{Patch and sample preparation}

The protocol used for the group specimens has been described previously by Hernández et al. (2011). Abdominal wall tissue patches were harvested using a template from each animal. The patch size was $60 \times 100[\mathrm{~mm}]$ with the long side perpendicular to the craniocaudal direction. One tissue patch was cut from the left of each animal (see Figure 2(a)). The mesh shrinkage was determined in the longitudinal and transverse directions. For this purpose, before their removal, we traced the outlines of the meshes on $40 \times 40[\mathrm{~mm}]$ transparent templates (the same dimensions as the original mesh). Using a calibrated system, a single measurement was then made in both directions on 4 patches at each time point. After measuring the mesh shrinkage, abdominal wall tissue patches were harvested from all animals (Figure 2). This was done by marking a $60 \times 60[\mathrm{~mm}]$ square on the abdominal wall of the rabbit using a transparent template (dashed line in Figure 2(b), slightly larger than the dimensions of the original prostheses). After 
harvesting, the patches were immersed in a saline solution at $4\left[{ }^{\circ} \mathrm{C}\right]$ until sample preparation to prevent them from drying out.

For the mechanical tests, three strips were obtained from each tissue patch (see Figure 2.c). Longitudinal strips were obtained from 3 patches and transverse strips from the remaining 3 patches. The total number of feasible strips is shown in Table 1. All tissue patches and strips were carefully examined and any with holes, cuts or apparent damage were rejected.

\subsection{Histological assessment and immunohistochemical analysis}

\subsubsection{Light microscopy}

After harvesting the strips for the mechanical tests, the tissue remaining in the patch was used for the histological study (see Figure 2.c). For light microscopy, tissue specimens obtained in the craniocaudal direction of the animal were fixed in F13 solution, embedded in paraffin and cut into $5[\mu \mathrm{m}]$ sections. Once cut, the sections were stained with Masson's trichrome (GoldnerGabe) and examined under a light microscope (Zeiss Axiophot, Carl Zeiss, Oberkochen, Germany).

\subsubsection{Collagen expression}

Collagen contents were determined in the same sections by Sirius red staining of collagen types I and III. This technique (Junqueira et al., 1978) is based on the orientation and interaction between the sulfone groups of the dye, the amine groups of lysin and hydrolysin, and the guanidine groups of arginine in the collagen fibres, giving rise to different colours depending on the type of collagen. Type I collagen, or mature collagen, appears as a reddish-orange stain, while type III collagen (immature) takes on a yellowish-green shade when observed under the polarized light microscope (Zeiss Axiophot, Carl Zeiss, Oberkochen, Germany).

For each type of collagen semiquantification of the staining was assessed in 10 digitalized histological images per animal that were captured using a digital camera fitted to the microscope (Axiocam HR, Zeiss) and analysed using Axiovision AC 4.1 image analysis software. Each section was divided into 4 zones, and one microscope field (x100) was randomly selected from each zone to estimate the extent of staining. The scale used for semiquantification was as follows: - , undetectable staining $(<10 \%) ; \pm$, minimum staining $(10-25 \%) ;+$, moderate staining $(25-50 \%) ;++$, strong staining $(50-75 \%) ;+++$, maximum staining $(75-90 \%)$ and ++++ , almost complete staining (>90\%).

\subsubsection{Macrophage response}

For immunohistochemistry, a specific monoclonal antibody to rabbit macrophages, RAM 11 (DAKO M-633, USA), was applied to parafin-embedded sections. The alkaline phosphatase- 
labelled avidin-biotin method was performed with the following steps: incubation with the primary antibody (1:50 in Tris-buffered saline (TBS)) for 30 minutes, incubation with immunoglobulin $\mathrm{G}$ and biotin (1:1,000 in TBS) for 45 minutes, and labelling with avidin (1:200 in TBS) for 30 minutes. These steps were conducted at room temperature. Images were developed with the use of a chromogenic substrate containing naphthol phosphate and fast red. Nuclei were counterstained for 5 minutes in acid haematoxylin. RAM 11-labelled macrophages were quantified by performing counts in 20 microscopic fields (x20) for each animal. Percentages of RAM-11 positive cells were compared among the different study groups using an independent t-test. The level of significance was set at $p<0.05$.

\subsection{Experimental characterization of Ciberlastic-muscle composite}

Sample lengths and widths were measured using a digital calliper. The measurements for each type of sample are shown in Table 2 . Uniaxial tensile tests were performed under displacement control on an INSTRON 3340 microtester with a $1[\mathrm{kN}]$ full scale load cell. Each abdominal muscle sample was preconditioned with three cycles at a nominal strain of $40 \%$ (Hernández et al., 2011). The applied displacement rate was $5[\mathrm{~mm} / \mathrm{min}]$ to preserve quasistatic testing

conditions. Stretch data were also computed as $\lambda=\frac{L_{0}+\Delta L}{L_{0}}$. The value of the thickness of the mesh could not be defined due to its discontinuous cross-sectional area, including filaments and interspersed empty areas. Therefore, stress could not be defined when testing the whole tissue-mesh. Instead, Equivalent Piola Stress was obtained.

Data were statistically compared among the groups to detect significant variations in the mechanical behaviour of the meshes and the healthy muscle tissue in both directions at all postimplant times. Mesh shrinkage in both directions was also compared. An independent t -test was used for all comparisons. The level of significance was set at $p<0.05$.

\section{Results}

The Ciberlastic mesh has two different size pores forming part of its design, but only the larger of these is shown in the image. The pore surface area is $7.1 \pm 1.6 \mathrm{~mm}^{2}$, and density is $29 \mathrm{~g} / \mathrm{m}^{2}$. The new design will be compared to a commercial polypropylene mesh, Optilene ${ }^{\circledR}$, a lightweight monofilament mesh $\left(48 \mathrm{~g} / \mathrm{m}^{2}\right)$ with a large pore size (pore surface area $=7.64 \pm 0.32 \mathrm{~mm}^{2}$ ).

Figure 4 shows the mean EPS vs. stretch curves obtained in the mechanical tests, which provides a meaningful comparisons between the new mesh (Ciberlastic) and Optilene ${ }^{\circledR}$ elastic. We found that tensile mechanical behaviour along direction 1 (D1) was significantly stiffer than along direction 2 (D2) for both meshes, see Table 3. EPS data revealed differences between the two meshes. After stretching the meshes by $50 \%$, Optilene ${ }^{\circledR}$ emerged as the stiffest mesh, showing membrane stresses of $1.797 \pm 0.418 \mathrm{~N} / \mathrm{mm}$ and $0.587 \pm 0.092 \mathrm{~N} / \mathrm{mm}$ for D1 and D2 directions, respectively. For the Ciberlastic mesh, the membrane tension at $50 \%$ was recorded 
as $0.116 \pm 0.038 \mathrm{~N} / \mathrm{mm}$ and $0.0039 \pm 0.0006 \mathrm{~N} / \mathrm{mm}$ for D1 and D2 directions, respectively, showing a diminished stiffness in D2. The maximum EPSs at break were $2.16 \pm 0.531 \mathrm{~N} / \mathrm{mm}$ and $0.845 \pm 0.084 \mathrm{~N} / \mathrm{mm}$ for Optilene ${ }^{\circledR}$ and $0.237 \pm 0.081 \mathrm{~N} / \mathrm{mm}$ and $0.073 \pm 0.017 \mathrm{~N} / \mathrm{mm}$ for Ciberlastic at D1 and D2, respectively. Also, the in vivo strength is also strongly decreased for the new mesh (Ciberlastic) showing a value ten times lower than the in vivo strength of Optilene ${ }^{\circledR}$.

\subsection{Shrinkage}

After surgical mesh implantation, the wound repair process causes shrinkage of the mesh. Consequently, the mesh size is reduced. Therefore, the shrinkage, which differs depending on the implanted surgical mesh, may limit the distensibility of the abdominal wall, which is a contributing factor for recurrences and patient discomfort.

Tables 4 and 5 provide the percentage of mesh shrinkage recorded in the longitudinal and transverse directions of the animals at the two post-implant time points. The shrinkage suffered by the Ciberlastic mesh was significantly greater in the transverse direction $(p<0.05)$ at each time point, and for the Optilene ${ }^{\circledR}$ mesh $(p<0.05)$, the shrinkage was greater in the longitudinal directions at 14 days. In both cases, the greater shrinkage occurs in the mesh's stiffer direction at 14 days.

\subsection{Morphological analysis}

None of the animals died, and there were no signs of infection and/or rejection in any of the implants. Macroscopically, the process of tissue integration was favoured at 180 days after implantation. At 14 days, encapsulation and lack of integration, primarily in some animals implanted with Ciberlastic mesh, was observed. In animals implanted with Optilene ${ }^{\circledR}$ tissue, integration was improved in the short term (Figure 5).

\subsubsection{Light microscopy}

In the animals implanted with the different mesh types, a similar wound healing process was observed at the different study times. In the short term and regardless of the composition of the mesh (PP/PUe), a loose, newly formed connective tissue that developed between the prosthetic filaments was observed in both groups. Despite the early development of this neo-tissue, it was richly vascularized and there was evidence of a moderate presence of inflammatory cells in the areas closest to the prosthetic filaments and in the areas surrounding the newly formed vessels (Figure 6). In the long term, the behaviour of the two meshes was also very similar. This newly formed connective tissue was infiltrated by adipose tissue, and at 180 days, this was the main tissue in the repair area. Richer in collagen fibres and much more dense, this connective tissue was primarily located in areas around the filaments of the prosthesis. The inflammatory reaction 
had decreased significantly from 14 days after implantation in both study groups regardless of the composition of the prosthetic material (Figure 6).

\subsubsection{Collagen expresion}

Following implantation of the mesh, it is desirable that a well-structured regenerated tissue with optimal synthesis and deposition of collagen (mainly type I, which helps to modulate and give strength to the repair area) will be formed around the filaments of the prostheses.

In the Ciberlastic mesh prototype, the Sirius Red staining indicated the predominance of type III collagen (immature, yellow) at 14 days in the extracellular matrix of newly formed tissue, showing strong staining with levels between 50-75\% and with only small areas corresponding to type I collagen (moderate levels between 25-50\%) at this study time. The predominance of mature collagen (type I, red) in the long term showed more specific areas of dense connective tissue around the prosthetic filaments with maximum staining showing levels between 75-90\%, while collagen III showed minimal expression (10-25\%) (Figure 7 and Table 6).

In Optilene ${ }^{\circledR}$ in the short term, areas of unstained extracellular matrix corresponding to nonfibrilar amorphous fundamental substance were observed around the prosthetic filaments. Collagen I deposition showed strong staining with levels between 50-75\% at this study time and between 25-50\% for the inmature type. Collagen I increased deposition in the long term showing maximum staining (75-90\%), while collagen III showed minimal expression (Figure 7 and Table 6).

\subsubsection{Macrophage response}

Macrophage response was more important in the short term and significantly decreased by 180 days after implantation in both study groups (Figure 8). Macrophage cells were observed in the newly formed tissue between the mesh filaments. The largest number of positive cells was concentrated around the mesh filaments, where multinucleated foreign-body giant cells, typical of a wound repair response, were also observed. The presence of inflammatory cells was also detected in areas of newly formed tissue near vascular areas that were more remote from the vicinity of the prosthetic filaments (Figure 8). No statistical differences in the macrophage response between the two meshes (Ciberlastic and Optilene ${ }^{\circledR}$ ) were found at either of the two study times. A significant decrease of the macrophage response was observed from 14 to 180 days in both prosthetic materials.

\subsection{Mechanical tests of mesh-muscle composite}

Figure 9 shows the EPS curves obtained for the partially herniated repaired muscle tissue by Ciberlastic and Optilene ${ }^{\circledR}$ meshes, presented as the mean \pm SD (standard deviation). It can be observed that both the Ciberlastic and Optilene ${ }^{\circledR}$ meshes were stiffer at 180 days than at 
14 days $(p<0.01$ and $p<0.01$, respectively). The mechanical responses shown by the nonimplanted meshes are far from the behaviour shown by the repaired muscle tissue such that the tissue became stiffer over time due to the growth of collagen over the hernial defect.

At 14 and 180 days post-implant, the implanted Ciberlastic mesh behaved similarly in both directions $(p>0.05)$. The longitudinal curves showed a larger SD than the transversal ones. In contrast, at 14 and 180 days post-implant, the response of the Optilene ${ }^{\circledR}$ mesh was anisotropic, and the longitudinal direction was stiffer than the transverse direction $(p<0.0469)$. The SD of the EPS curves was almost the same magnitude for all directions and for both short and long term. Typical exponential dependency of the EPS curves of the Ciberlastic mesh is presented with high stiffness at higher levels of stretch. However, for Optilene ${ }^{\circledR}$ mesh, this tendency is less pronounced, showing a softening behaviour (decreasing the stiffness) at higher levels of stretch due to delamination of the muscle tissue.

\section{Discussion}

Some studies regarding the most appropriate mesh for hernia repair (Brown and Finch, 2010b) have indicated that the most important properties are the type of filament, tensile strength and porosity. These features determine the weight of the mesh and its biocompatibility. The mesh pore size has been identified as critical for tissue integration, with decreased intensity of inflammation, fibrosis, risk of infection and shrinkage associated with larger pores (Conze et al., 2008). Some authors (Müehl et al., 2008) have described the concept of effective porosity by identifying pores as sufficiently large so that bridging of the foreign-body reaction from one filament to another does not occur. These lightweight meshes were introduced in the field of hernia repair some years ago, and their superiority due to their increased flexibility and reduction in discomfort over other prostheses is currently widely accepted. However, they continue to have complications, such as recurrences, infection and adhesion formation, and the ideal mesh has not yet been developed. The implanted meshes have to allow a certain degree of stability and stretchability at the same time (Lambertz et al., 2015) because the anatomy of the abdominal wall requires some degree of flexibility (Junge et al., 2001, Smietanski et al., 2012). The use of non-elastic materials, despite the tension-free procedures that are commonly employed in these repair techniques, might cause pain and hernia recurrence because of shearing stresses between the flexible anatomy of the abdomen and the stiffer prosthesis (Binnebösel et al., 2007, Shankaran et al., 2011). Taking all these considerations into account, the aims of this study were to develop a new elastic lightweight mesh that would mimic the properties of the abdominal wall and that was constructed from non-absorbable polyurethane (PUe) monofilaments (Assuplus ${ }^{\circledR}$, Assut Europe, Italy (PUE)) with elastic properties and to examine its in vivo behaviour in preclinical studies in a rabbit model compared with another commercial LW prosthesis $\left(\right.$ Optilene ${ }^{\circledR}$ ) that had a similar design and porosity but was developed with PP.

The idea of a mesh with elastic properties is truly groundbreaking and innovative. In the literature, there are only two recent publications, both by the same research group (Lambertz et al., 2015, 2016), that refer to these type of meshes with elastic properties, although there 
are major differences in our design. The mesh was constructed using polyvinylidene fluoride (PVDF) with elastic thermoplastic polyurethane (TPU) filaments. The first paper (Lambertz et al., 2015) is an inlay performance after midline laparotomy, which is a short-term preclinical evaluation, and the authors focused on avoiding pore size changes under mechanical strain because of the inelasticity of current meshes. The paper indicated that the newly developed mesh shows elasticity, structural stability, and preserved effective porosity under mechanical strain, exhibiting superior biocompatibility compared with PVDF meshes in the short term. The results showed that the number of macrophages, cell proliferation and apoptotic cells were significantly lower in the TPU group after 7 and 14 days compared with PVDF, which the authors interpreted as superior biocompatibility. In our case, however, no differences were observed in macrophage response between the two meshes, and a similar wound healing process, regardless of the composition of the mesh, was observed at the different study times.

The second study (Lambertz et al., 2016) is a preclinical evaluation of the adhesion formation of the same new elastic mesh compared to PP meshes in an IPOM (intraperitoneal onlay mesh) position. The authors showed a reduction in the peritoneal adhesion formation with the newly developed elastic mesh compared to PP meshes after 7 and 21 days, with similar biocompatibility of the two meshes used in a similar way to our study. In our model, the new prosthesis designed by our group, with the added advantage of the flexibility of the filament, achieved similarly good behaviour to that shown by one of the most popular LW prostheses on the market, Optilene ${ }^{\circledR}$, which uses the term "elastic" because its design allow it to cover a large deformation, but the filament forming the mesh has no elastic property at all. It is true that the mechanical properties are significantly lower than in the PP Optilene ${ }^{\circledR}$ mesh, but the new elastic mesh meets the basic mechanical requirements for positioning in the abdominal wall, which is also demonstrated by the absence of recurrences after implantation in the experimental model.

The increase in mechanical stiffness at 14 and 180 days is greater for the Ciberlastic mesh than the Optilene ${ }^{\circledR}$ mesh. The contribution of collagen to the stiffness of the Optilene ${ }^{\circledR}$ mesh is probably negligible compared to that of the mesh alone (Hernández-Gascón et al., 2011, 2012), whereas this contribution is much more marked for the Ciberlastic mesh due to its inherently low stiffness. Our observations suggest that the repair process induced by placement of the Ciberlastic mesh is modulated by ingrowing host tissue. We found that the growth of a connective tissue rich in collagen over the hernial defect, and the proper deposit of the collagen fibres in the regenerated tissue, substantially modified the original properties of the mesh, increasing their biomechanical strength and making the whole tissue/mesh stiffer. In the animals implanted with Ciberlastic, the deposition of collagen type I in the newly formed tissue, which is the one that mainly give strength to the repair area increasing tissue resistance, significantly increased their levels over time, corresponding to the increase of mechanical strength already mentioned. In this group, moderate expression between 25-50\% was noted at 14 days after implantation, that is considerably increased at 6 months showing maximal expression with levels between $75-90 \%$.

In addition to the meshes developed with elastic materials, other concepts of dynamic meshes have been introduced in the literature. Amato et al. (2012) achieved excellent outcomes in a 
porcine model with a fixation-free inguinal hernia repair using a dynamic self-retaining implant and demonstrated that the dynamic compliant movement and recoil of this 3D prosthetic structure within the groin's natural tissues allowed for the critical cyclical physiologic loading that is missing with other implants. The same group has recently published a clinical comparative study of conventional static meshes versus 3D dynamic implants (Amato et al., 2015), in which the implant showed development of optimal ingrowth of loose connective tissue, wellformed vascular structures, elastic fibres and even mature nerves with a negligible inflammatory response.

Our experimental study has several obvious limitations. The first is related to the animal model, which may not be representative of humans in terms of either size or species. Another important limitation is that the defect was created in an abdominal wall that was free of anatomic obstacles, and the different meshes were implanted in optimal conditions, allowing for their easy adaptation to the abdominal wall. In clinical practice, the situation is not as ideal. Our animal model of partial thickness excision of the abdominal wall have been previously validated by our group and this fact can be corroborated by numerous publications. Rather than a hernia model, our model is one of acute wound repair using a mesh that is closely related and have strong implication to hernia repair. Additional limitations of this study include the limited sample number. All the experiments in this study were performed in accordance with national ethical guidelines and the directives of the European Council that recommend minimizing the number of animals used in trial experiments. Statistical tests showing statistical significance are somewhat meaningless given the very small sample sizes. Additionally, information provided by other types of tests (e.g., biaxial tests) would be useful to complement our tissue characterization. Biaxial tests reproduce the physiological deformation and loading conditions of muscle tissue.

However, despite the dificult translation to the clinical setting, the observations of our study provide insight into the potential of these new elastic materials with optimal biocompatibility that mimic and restore the functional characteristics of the abdominal wall.

\section{Acknowledgements}

This study was supported by the Spanish Ministry of Science and Technology through research projects DPI2011-27939, DPI2014-54981-R, DPI2013-44391-P and SAF-2014-55022-P; the Department of Industry and Innovation (Government of Aragon) through the research group Grant T88 (Fondo Social Europeo) and the Instituto de Salud Carlos III (ISCIII) through the CIBER initiative (BIOMIMESH project). The work was performed by the ICTS "NANBIOSIS" specifically by the Tissue \& Scaffold Characterization Unit (U13), of the CIBER in Bioengineering, Biomaterials \& Nanomedicne (CIBER-BBN at the University of Zaragoza). No conflicts of interest are declared. 


\section{References}

Amato, G., Agrusa, A., Romano, G., 2012. Fixation-free inguinal hernia repair using a dynamic self-retaining implant. Surg Technol Int 22, 107-112.

Amato, G., Romano, G., Agrusa, A., Marasa, S., Cocorullo, G., Gulotta, G., Goetze, T., Puleio, R., 2015. Biologic response of inguinal hernia prosthetics: a comparative study of conventional static meshes versus 3d dynamic implants. Artif Organs 39, E10-E23.

Bellón, J. M., Rodríguez, M., García-Honduvilla, N., Gómez-Gil, V., Pascual, G., Buján, J., 2009. Comparing the behavior of different polypropylene meshes (heavy and lightweight) in an experimental model of ventral hernia repair. Journal of Biomedical Materials Research. Part B, Applied Biomaterials 89B(2), 448-55.

Binnebösel, M., Rosch, R., an T. Flanagran, K. J., an V. Schumpelick, R. S., Klinge, U., 2007. Biomechanical analyses of overlap and mesh dislocation in ana incisional hernia model in vivo. Surgery 142(3), 365-71.

Brown, C., Finch, J., 2010a. Which mesh for hernia repair? Annals of The Royal College of Surgeons of England 92 (4), 272-278.

Brown, C. N., Finch, J. G., 2010b. Which mesh hernia repair? CollSurg Engl 92, 272-278.

Cobb, W. S., Burns, J. M., Peindl, R. D., Carbonell, A. M., Matthews, B. D., Kercher, K. W., Heniford, B. T., 2006. Textile analysis of heavy-weight, mid-weight and light-weight polypropylene mesh in a porcine ventral hernia model. Journal of Surgical Research 136, 1-7.

Conze, J., Junge, K., Weiss, C., Anurov, M., Oettinger, A., Klinge, U., Schumpelick, V., 2008. New polymer for intra-abdominal meshes-pvdf copolymer. J Biomed Mater Res B Appl Biomater 87, 321-328.

Conze, J., Kingsnorth, A. N., Flament, J. B., Simmermacher, R., Arlt, G., Langer, C., Schippers, E., Hartley, M., Schumpelick, V., 2005. Randomized clinical trial comparing lightweight composite mesh with polyester or polypropylene mesh for incisional hernia repair. British Journal of Surgery 92 (12), 1488-1493.

Conze, J., Klinge, U., 1999. Biocompatibility of biomaterials-clinical and mechanical aspects. Springer, Berlin, Heidelberg, New York, Ch. 14, pp. 169-177.

EU Hernia Trialists Collaboration, 2002. Repair of groin hernia with synthetic mesh: metaanalysis of randomized controlled trial. Ann Surg 235 (3), 322-332.

Hernández, B., Peña, E., Pascual, G., Rodriguez, M., Calvo, B., Doblaré, M., Bellón, J. M., 2011. Mechanical and histological characterization of the abdominal muscle. A previous step to model hernia surgery. J Mech Behav Biomed 4, 392-404.

Hernández-Gascón, B., Peña, E., Melero, H., Pascual, G., Doblaré, M., M. P. Ginebra, M. P., Bellón, J., Calvo, B., 2011. Mechanical behaviour of synthetic surgical meshes: finite element simulation of the herniated abdominal wall. Acta Biomater 7, 3905-3913.

Hernández-Gascón, B., Peña, E., Pascual, G., Rodríguez, M., Bellón, J., Calvo, B., 2012. Longterm anisotropic mechanical response of surgical meshes used to repair abdominal wall defects. J Mech Behav Biomed 5, 257-271.

Hilger, W. S., Walker, A., Zobitz, M. E., Leslie, K. O., Magtibay, P., Cornella, J., 2006. Histological and biomechanical evaluation of implanted graft materials in a rabbit vaginal and abdominal model. American Journal of Obstetrics and Gynecology 195, 1826-1831.

Johnson, E. K., Hoyt, C. H., Dinsmore, R. C., 2004. Abdominal Wall Hernia Repair: a LongTerm Comparison of Sepramesh and Dualmesh in a Rabbit Hernia Model. American Journal 
of Surgery 70(8), 657-61.

Judge, T. W., Parker, D. M., Dinsmore, R. C., 2007. Abdominal Wall Hernia Repair: a Comparison of Sepramesh and Parietex Composite Mesh in a Rabbit Hernia Model. Journal of the American College of Surgeons 204(2), 276-81.

Junge, K., Klinge, U., Prescher, A., Giboni, P., Niewiera, M., Shumpelick, V., 2001. Elasticity of the anterior abdominal wall and impact for reparation of incisional hernia using mesh implants. Hernia 5, 112-118.

Junqueira, L. C., Cossermelli, W., Brentani, R., 1978. Differential staining of collagen type I, II and III by Sirius Red and polarization microscopy. Archivum histologicum Japonicum 41, 267-274.

Klinge, U., 2008. Mesh for hernia repair. Br J Surg 95, 539-540.

Klinge, U., Klosterhalfen, B., Birkenhauer, V., Junge, K., Conze, J., Schumpelick, V., 2002. Impact of polymer pore size on the interface scar formation in a rat model. Journal of Surgical Research 103, 208-214.

Lambertz, A., v. a. Hil, L., Binnebósel, D. S. S. M., , Kroh, A., Klinge, U., Neumann, U. P., Klink, C. D., 2016. Analysis of adhesion formation of a new elastic thermoplastic polyurethane (tpu) mesh in comparison to polypropylene (pp) meshes in ipom position. J Mech Behav Biomed 53, 366-372.

Lambertz, A., Vogels, R. M., Binnebósel, M., Schób, D. S., Kossel, K., Klinge, U., Neumann, U. P., Klink, C. D., 2015. Elastic mesh with thermoplastic polyurethane filaments preserves effective porosity of textile implants. J Biomed Mater Res A 103, 2654-2660.

LeBlanc, K. A., Bellanger, D., 5th, K. V. R., Baker, D. G., Stout, R. W., 2002. Tissue attachment strength of prosthetic meshes used in ventral and incisional hernia repair. A study in the New Zealand White rabbit adhesion model. Surgical Endoscopy 16(11), 1542-6.

Luijenkijk, R. W., Hop, W. C., den Tol, M. P. V., 2000. A comparison of suture repair with mesh repair for incisional hernia. New England Journal of Medicine 343, 392-398.

Müehl, T., Binnebssel, M., Klinge, U., Goedderz, T., 2008. New objective measurement to characterize the porosity of textileimplants. J Biomed Mater Res B Appl Biomater 84, 176183.

Nilsson, T., 1982a. Biomechanical studies of rabbit abdominal wall. Part I.- The mechanical properties of specimens from different anatomical positions. Journal of Biomechanics 15 (2), $123-129$.

Nilsson, T., 1982b. Biomechanical studies of rabbit abdominal wall. Part II.- The mechanical properties of specimens in relation to length, width, and fibre orientation. Journal of Biomechanics 15 (2), 131-135.

O’Dwyer, P. J., Kingsnorth, A. N., Molloy, R. G., Small, P. K., Lammers, B., Horeyseck, G., 2005. Randomized clinical trial assessing impact of a lightweight or heavyweight mesh on chronic pain after inguinal hernia repair. British Journal of Surgery 92 (2), 166-170.

Pascual, G., Hernández-Gascón, B., Rodríguez, M., Sotomayor, S., Peña, E., Calvo, B., Bellón, J. M., 2012. The long term behavior of lightweight and heavyweight meshes used to repair abdominal wall defects is determined by the host tissue repair process provoked by the mesh. Surgery 52(5), In 886-95.

Pascual, G., Rodríguez, M., Gómez-Gil, V., García-Honduvilla, N., Buján, J., Bellón, J. M., 2008. Early tissue incorporation and collagen deposition in lightweight polypropylene meshes: bioassay in an experimental model of ventral hernia. Surgery 144, 427-35. 
Pierce, L. M., Grunlan, M. A., Hou, Y., Baumann, S. S., Kuehl, T. J., Muir, T. W., 2009. Biomechanical properties of synthetic and biologic graft materials following long-term implantation in the rabbit abdomen and vagina. Americal Journal of Obstetrics and Ginecology 200, 549.e1-549.e8.

Poobalan, A. S., Smith, J. B. W. C., King, P. M., Krukowski, Z. H., Chambers, W. A., 2003. A review of chronic pain after inguinal herniorrhaphy. Clin J Pain 19, 48-54.

Shankaran, V., Weber, D. J., Reed, R. L., Luchette, F. A., 2011. A review of available prosthetics for ventral hernia repair. Ann Surg 253, 16-26.

Simón-Allué, R., Pérez-Lópezc, P., Sotomayor, S., Peña, E., Pascual, G., Bellón, J., Calvo, B., 2014. Short- and long-term biomechanical and morphological study of new suture types in abdominal wall closure. J Mech Behav Biomed 37, 1-11.

Smietanski, M., Bury, K., Tomaszewska, A., Lubowiecka, I., Szymczak, C., 2012. Biomechanics of the front abdominal wall as a potential factor leading to recurrence with laparoscopic ventral hernia repair. Surg Endosc 26, 1461-1467. 


\begin{tabular}{ccccc} 
Mesh & & scaffold & 14 Days & 180 Days \\
\hline \hline \multirow{2}{*}{ Ciberlastic } & LONG & 5 & 9 & 9 \\
& TRANS & 5 & 9 & 9 \\
\hline
\end{tabular}

Table 1

Number of feasible strips obtained in both directions for the mechanical test. 


\begin{tabular}{ccccc} 
Tissue & Sample & $\begin{array}{c}\text { Length } \\
{[\mathrm{mm}]}\end{array}$ & $\begin{array}{c}\text { Width } \\
{[\mathrm{mm}]}\end{array}$ & $\begin{array}{c}\text { Thickness } \\
{[\mathrm{mm}]}\end{array}$ \\
\hline \multirow{2}{*}{14 days } & LONG & $74.711 \pm 3.956$ & $9.296 \pm 0.959$ & $1.985 \pm 0.483$ \\
& TRANS & $69.529 \pm 2.767$ & $9.347 \pm 0.763$ & $1.831 \pm 0.392$ \\
\hline \multirow{2}{*}{180 days } & LONG & $86.279 \pm 10.477$ & $10.486 \pm 1.718$ & $3.095 \pm 1.376$ \\
& TRANS & $71.778 \pm 5.116$ & $9.858 \pm 1.452$ & $3.665 \pm 0.734$ \\
\hline
\end{tabular}

Table 2

Average dimensions of the mesh (scaffold) and implanted tissue/mesh strips obtained from the control rabbits (mean \pm standard deviation). 


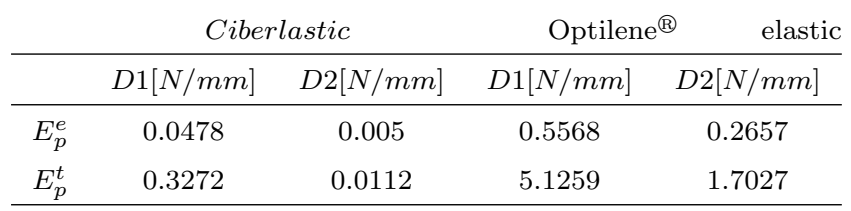

Table 3

Average properties for the different meshes in directions D1 and D2. The stiffness of the scaffold at different stretch levels was defined as the slope of the stress-stretch curve, $E_{p}=\frac{\Delta E P S[N / m m]}{\Delta \lambda}$. Two different moduli were defined depending on the computed stretch levels. Elastic modulus which shows the stiffness at low stretches or $E_{p}^{e}$ (computed at $\lambda=1.01$ ) and tangent modulus at high stretches or $E_{p}^{t}$ (computed at $\left.\lambda=1.3\right)$ 


\begin{tabular}{ccccc} 
& \multicolumn{2}{c}{ Ciberlastic } & \multicolumn{2}{c}{ Optilene $^{\circledR}$} \\
\hline & LONG[\%] & TRANS[\%] & LONG[\%] & TRANS[\%] \\
\hline Patch 1 & 0 & 12 & 13 & 5 \\
Patch 2 & 2 & 25 & 13 & 5 \\
Patch 3 & 2 & 20 & 13 & 0 \\
Patch 4 & 5 & 25 & 25 & 0 \\
\hline Mean & 2.25 & $20.5^{*, * *}$ & $16^{*, * *}$ & 2.5 \\
SD & 2.06 & 6.13 & 6 & 2.88 \\
\hline
\end{tabular}

Table 4

Mesh shrinkage observed at 14 days post-implant. ${ }^{*} p<0.05$ means significant differences between directions in the same group and ${ }^{* *} p<0.05$ means significant differences between same directions in different groups 


\begin{tabular}{ccccc} 
& \multicolumn{2}{c}{ Ciberlastic } & \multicolumn{2}{c}{ Optilene $^{\circledR}$} \\
\hline & LONG[\%] & TRANS[\%] & LONG[\%] & TRANS[\%] \\
\hline Patch 1 & 1 & 9 & 0 & 0 \\
Patch 2 & 1 & 10 & 0 & 0 \\
Patch 3 & 0 & 8 & 0 & 0 \\
Patch 4 & 0 & 7 & 13 & 0 \\
\hline Mean & 0.5 & $8.5^{*, * *}$ & $3.25^{*, * *}$ & 0 \\
SD & 0.52 & 4.5 & 6.5 & 0 \\
\hline \hline
\end{tabular}

Table 5

Mesh shrinkage observed at 180 days post-implant. ${ }^{*} p<0.05$ means significant differences between directions in the same group and ${ }^{* *} p<0.05$ means significant differences between same directions in different groups. 


\begin{tabular}{cccc} 
Mesh & & 14 days & 180 days \\
\hline Ciberlastic & Collagen I & + & +++ \\
& Collagen III & ++ & \pm \\
\hline Optilene ${ }^{\circledR}$ & Collagen I & ++ & +++ \\
& Collagen III & + & \pm \\
\hline
\end{tabular}

Table 6

Semiquantification of collagen I and III expression in the newly formed tissue in the implant area. The scale used for semiquantification was as follows: -, undetectable staining (i 10\%); \pm , minimum staining $(10-25 \%) ;+$, moderate staining $(25-50 \%) ;++$, strong staining $(50-5 \%) ;+++$, maximum staining (75-90\%) and ++++ , almost complete staining $(>90 \%)$. 

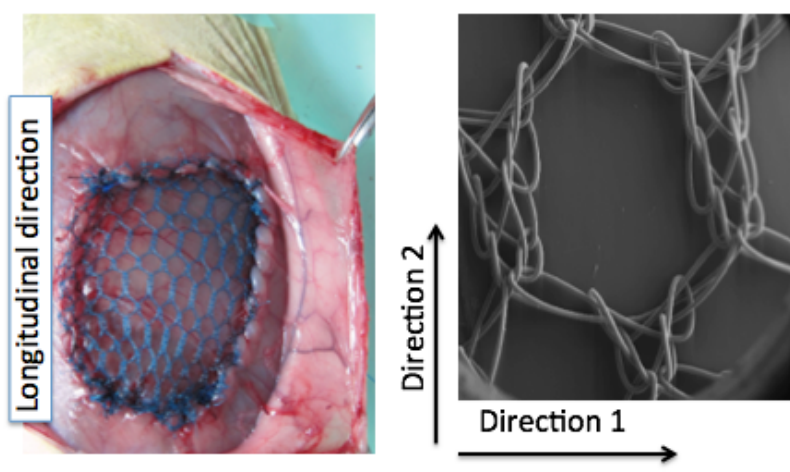

(a) Ciberlastic mesh
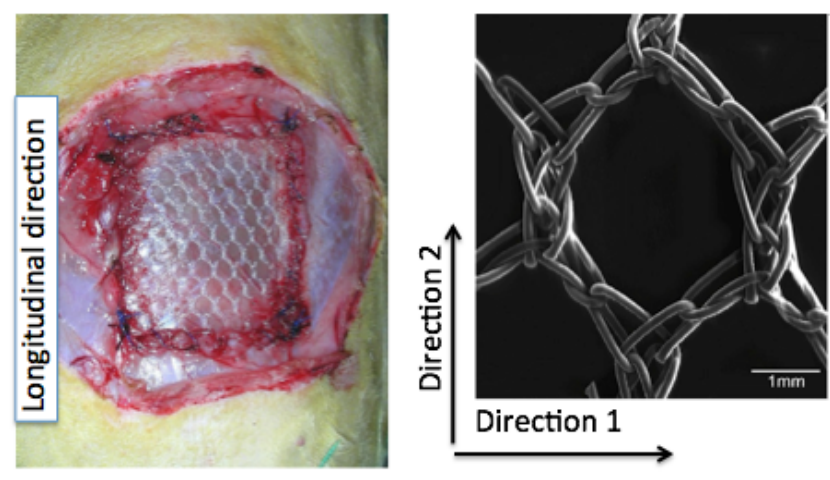

(b) Optilene ${ }^{\circledR}$ mesh

Fig. 1. Details of the two implanted meshes showing the defined directions 1 and 2 and the orientation in the rabbit. D1 corresponds to transversal direction and D2 corresponds to longitudinal direction 


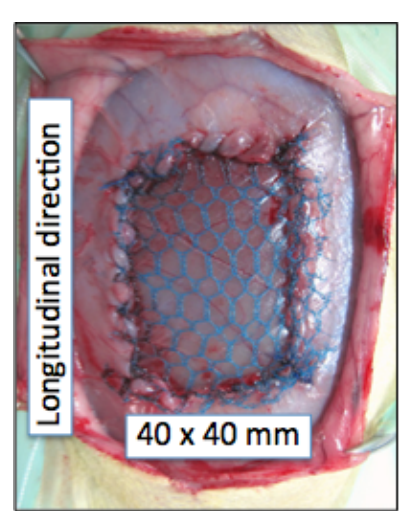

(a)

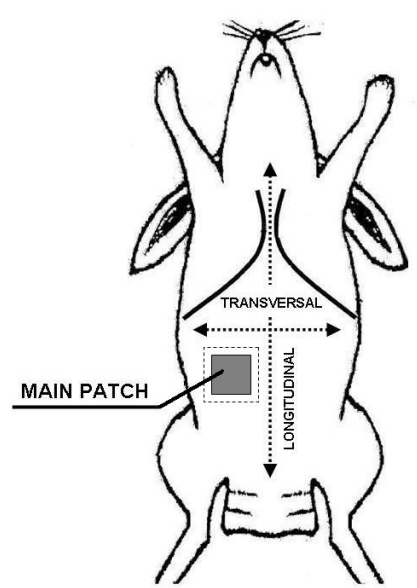

(b)

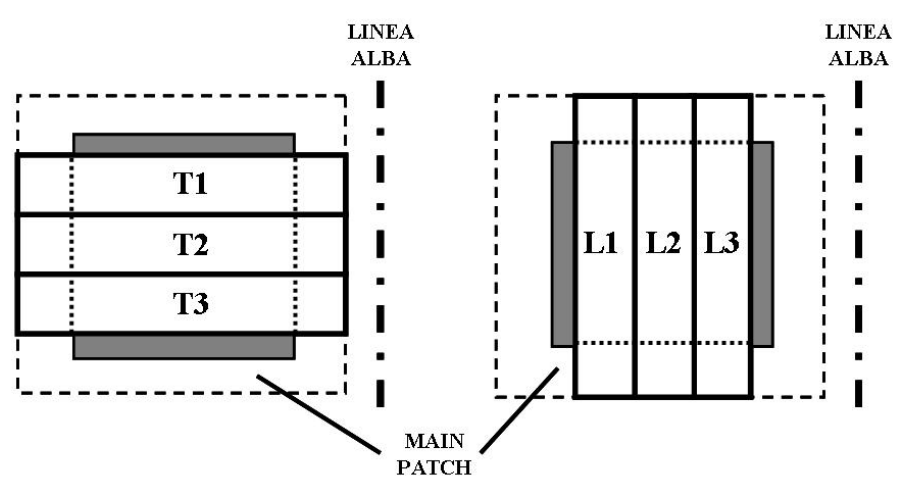

(c)

Fig. 2. (a) Placement of the prosthesis indicating the longitudinal direction . (b) Longitudinal (craniocauda) and transverse (perpendicular) directions defined in the rabbit. The grey area is the implant site and the outer dotted line is the cutting line used to harvest the main patch. (b) The main patch was cut into three strips in the transverse (left) or longitudinal (right) direction. The fine dotted lines on the strips are the sutures. Specimens for histology were obtained from the grey areas. 

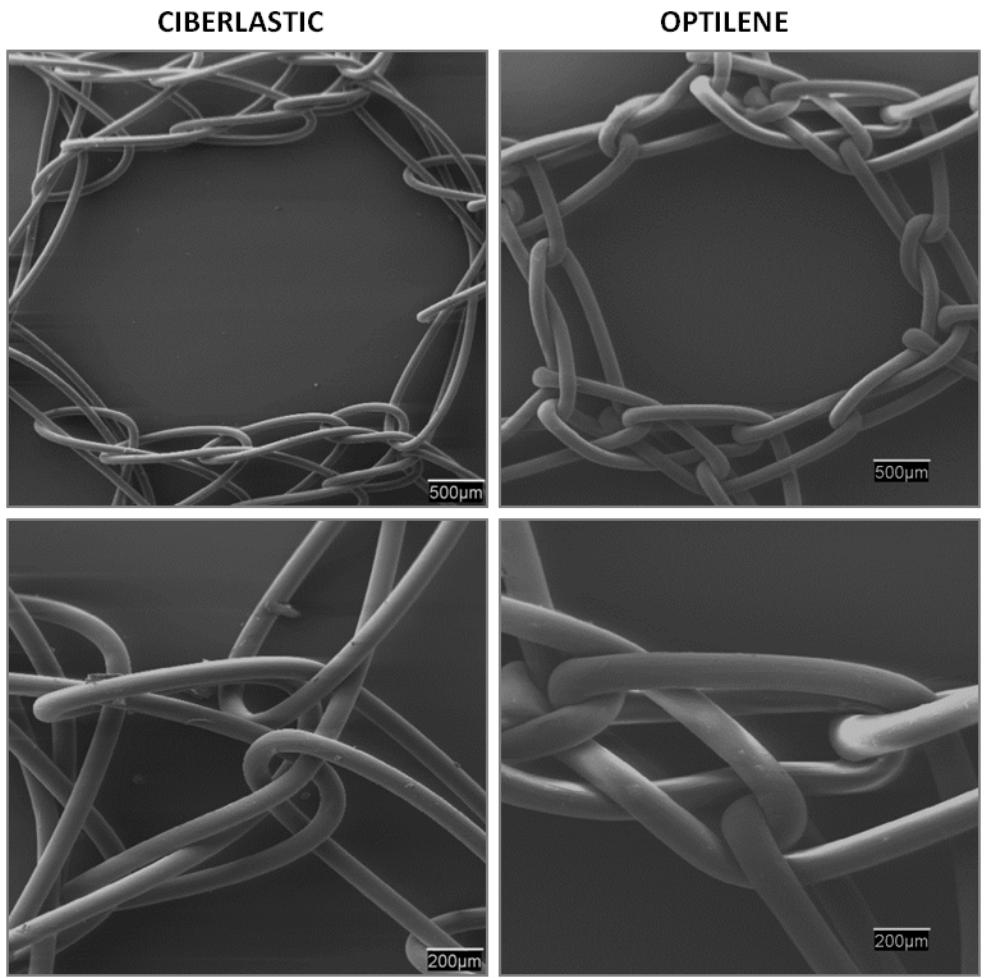

Fig. 3. Details of the new mesh (Ciberlastic) and the Optilene ${ }^{\circledR}$ elastic mesh. 


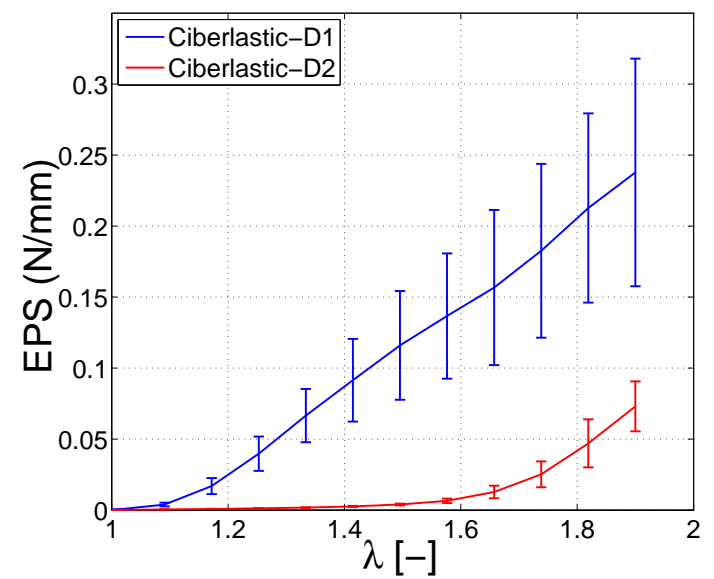

(a) Ciberlastic mesh

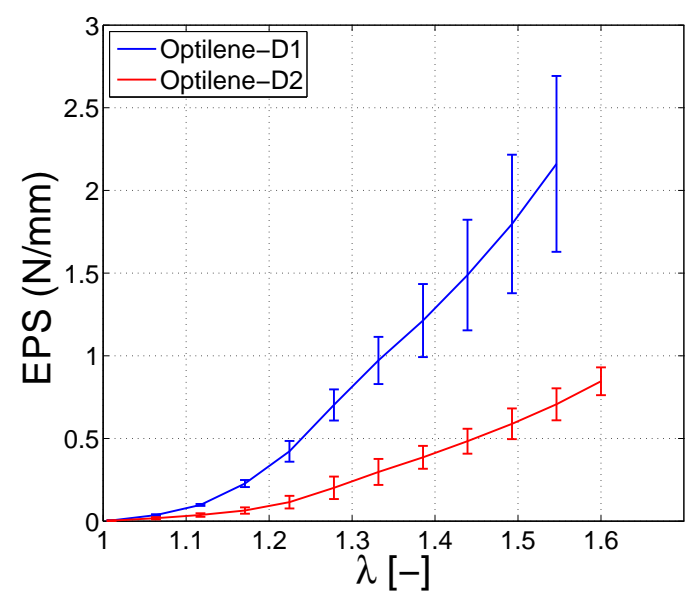

(b) Optilene ${ }^{\circledR}$ elastic mesh

Fig. 4. Experimental data obtained in the uniaxial tests for the two meshes. All experimental curves were truncated before the maximum stress point. 

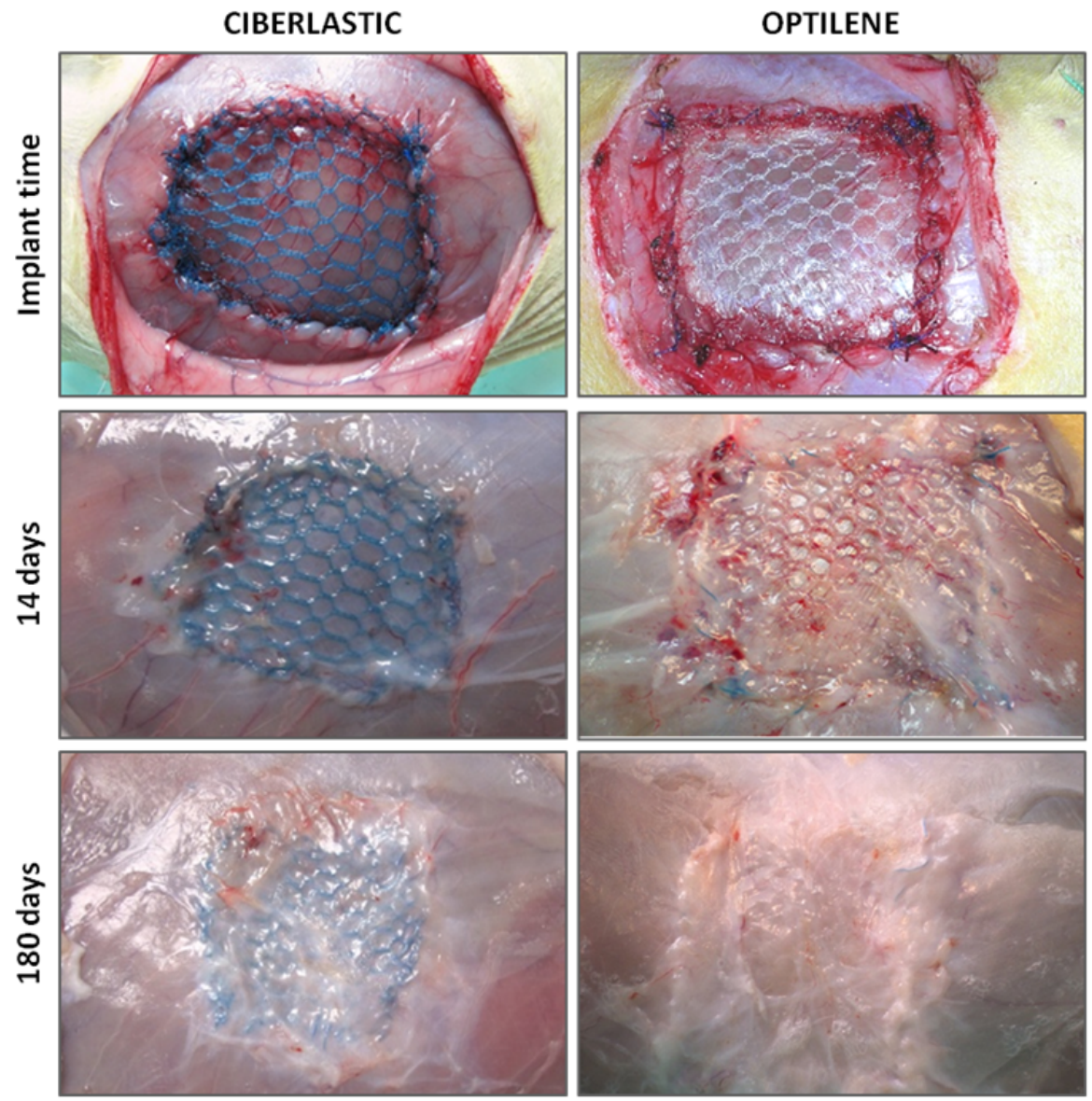

Fig. 5. Implanted biomaterials: Ciberlastic (left) and Optilene ${ }^{\circledR}$ elastic (right) after 0, 14 and 180 days of implant in the experimental animals. 


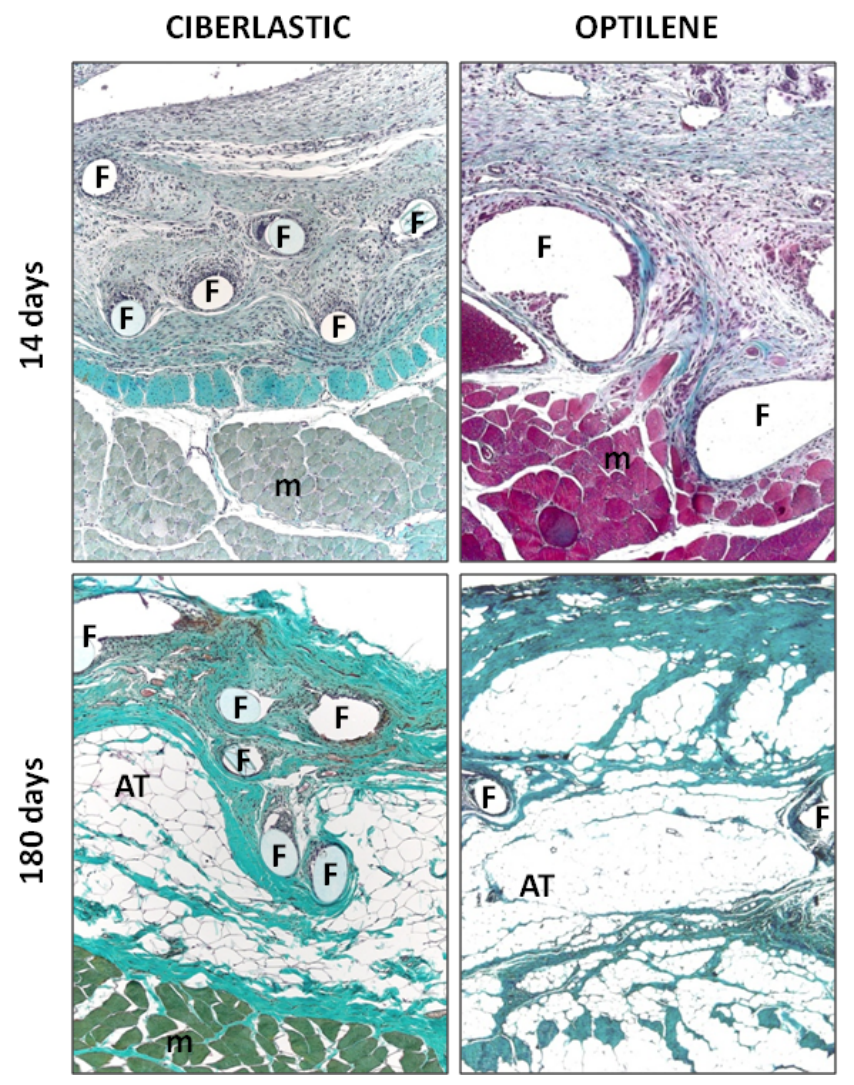

Fig. 6. Histological findings on Masson's trichrome staining of the two implanted meshes: Ciberlastic (left) and Optilene ${ }^{\circledR}$ (right) after 14 and 180 days of implant in the experimental animals. Ciberlastic 14 days, magnification 100X; Ciberlastic 180 days, magnification 100X; Optilene 14 days, magnification 100X and Optilene 180 days, magnification 50X. (F: prosthetic filaments, AT: adipose tissue. m: muscle tissue). 

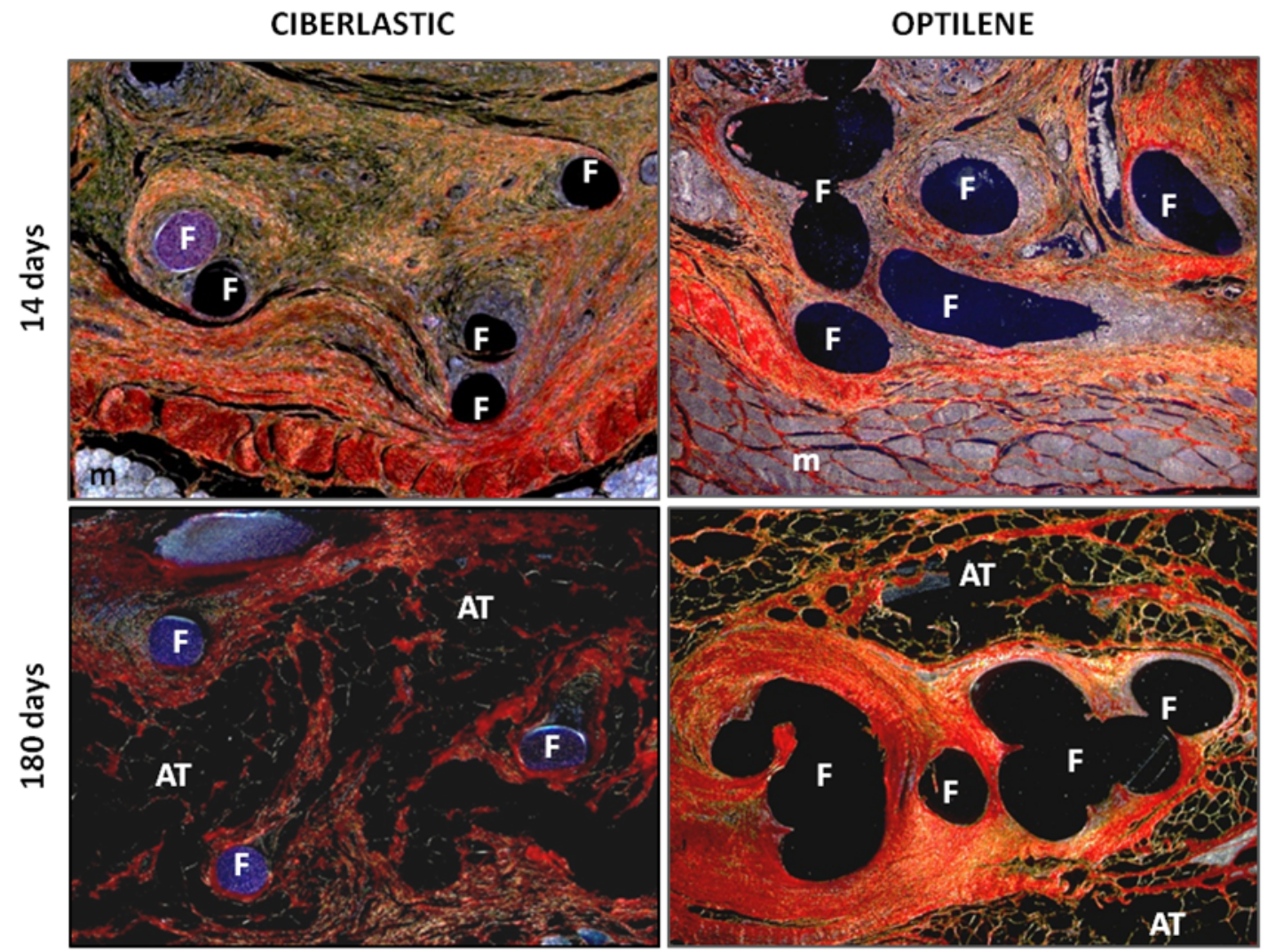

Fig. 7. Sirius red staining of Ciberlastic (left) and Optilene ${ }^{\circledR}$ (right) meshes at 14 and 180 days post-implant. Collagen III appears yellow, while collagen I (mature collagen) stains red. Ciberlastic 14 days, magnification 100X; Ciberlastic 180 days, magnification 100X; Optilene 14 days, magnification 100X and Optilene 180 days, magnification 100X 


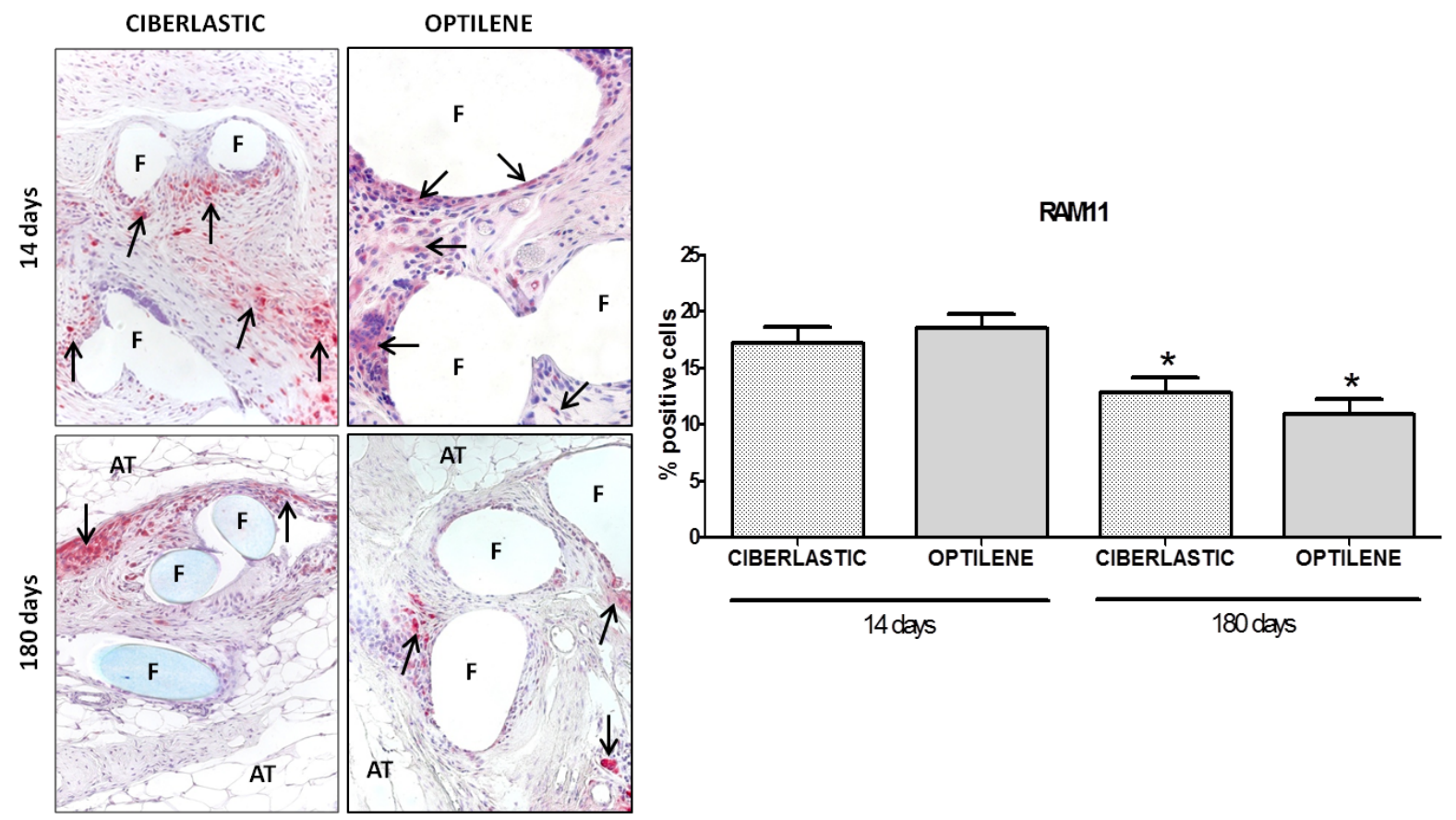

Fig. 8. Immunohistochemical labelling of rabbit macrophages (red colour, arrows) using the RAM 11 monoclonal antibody (left). Ciberlastic 14 days, magnification 200X; Ciberlastic 180 days, magnification 200X; Optilene 14 days, magnification 200X and Optilene 180 days, magnification 200X. Percentages of positive cells observed for the different implants at 14 and 180 days (right). (F: prosthetic filaments, AT: adipose tissue) $\left({ }^{*} p<0.05\right)$. 


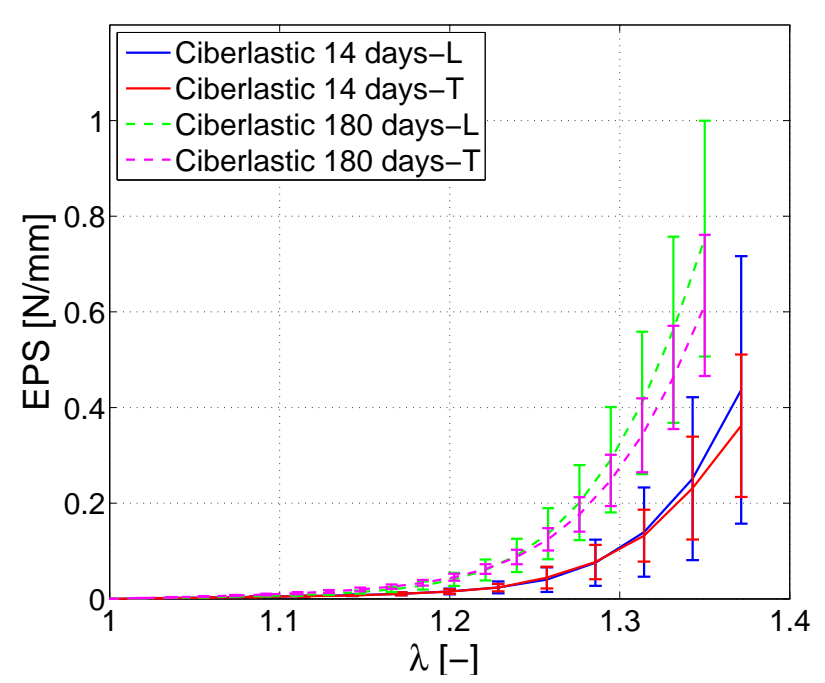

(a) Ciberlastic mesh

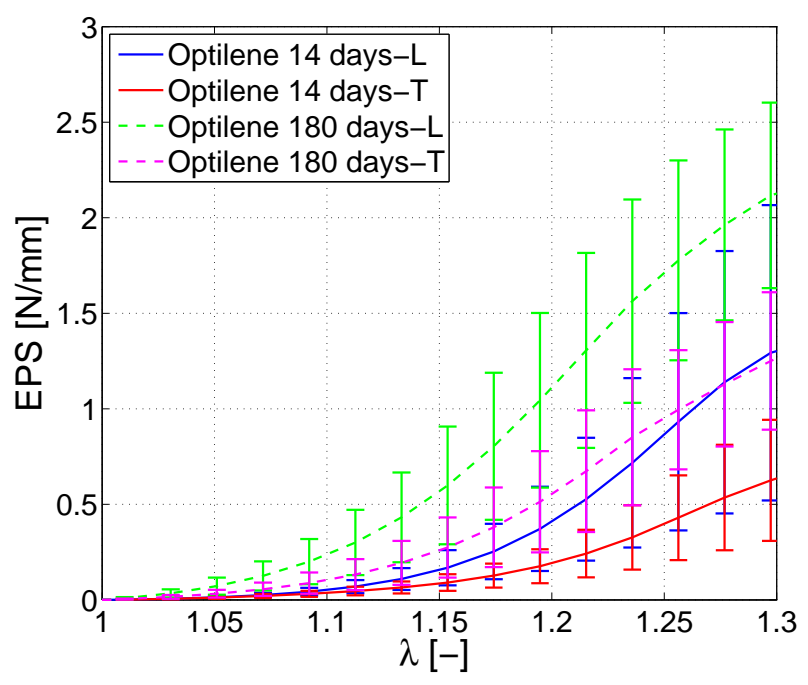

(b) Optilene ${ }^{\circledR}$ mesh

Fig. 9. EPS curves obtained in the mechanical tests for Ciberlastic (a) and Optilene ${ }^{\circledR}$ (b) meshes. 